NASA Technical Memorandum 87228

\title{
Two-Phase Flows and Heat Transfer Within Systems With Ambient Pressure Above the Thermodynamic Critical Pressure
}

R.C. Hendricks

Lewis Research Center

Cleveland, Ohio

M.J. Braun

University of Akron

Akron, Ohio

R.L. Mullen

Case Western Reserve University

Cleveland, Ohio

Prepared for the

Eighth International Heat Transfer Conference

San Francisco, California, August 17-22, 1986 
TWO-PHASE FLOWS AND HEAT TRANSFER WITHIN SYSTEMS WITH AMBIENT PRESSURE ABOVE THE THERMODYNAMIC CRITICAL PRESSURE

\author{
R.C. Hendricks \\ National Aeronautics and Space Administration \\ Lewis Research Center \\ Cleveland, Ohio 44135 \\ M.J. Braun \\ University of Akron \\ Akron, Ohio 44325 \\ R.L. Mullen \\ Case Western Reserve University \\ Cleveland, Ohio 44106
}

In systems where the design inlet and outlet pressures $P_{\text {amb }}$ are maintained above the thermodynamic critical pressure $P_{C}$, it is often assumed that heat and mass transfer are governed by single-phase relations and that two-phase flows cannot occur. This simple rule of thumb is adequate in many low-power designs but is inadequate for high-performance turbomachines, boilers, and other systems where two-phase regions can exist even though $P_{a m b}>P_{c}$. Heat and mass transfer and rotordynamic-fluid-mechanic restoring forces depend on momentum differences; and those for a two-phase zone can differ significantly from those for a single-phase zone. By using a laminar, variable-property bearing code and a rotating boiler code, pressure and temperature surfaces were determined that illustrate nesting of a two-phase region within a supercritical pressure region. The method of corresponding states is applied to bearings with reasonaile rapport (within 5 percent for an oxygen/nitrogen example).

\section{INTRODUCTION}

As a rule of thumb the extent and nature of the cavity formed downstream of a conventional inlet and the minimum clearance in a bearing or seal can be controlled, even eliminated, by increasing the ambient pressure. Often systems are operated above the thermodynamic critical pressure in an effort to circumvent two-phase flow and cavity formation. Uncertainties in stability, load capacity, heat transfer, fluid mechanics, and thermophysical property variations are thereby avoided.

Flow cavities are engendered by local departures from classical thermodynamics, termed "metastabilities." Classic among these are the work of Skripov [1] and applied work such as fracture, boiling, and condensing $[2,3]$. In many cases a two-phase flow cavity enhances bearing stability $[4,5]$ and seal load capacity [6]. The inception of cavity flow is important to both turbomachine stability and load capacity.

In bearings or eccentric shaft seals the

fluid is compressed in the convergent geometry (maximum pressure is reached before the minimum clearance) and expanded to subambient pressure.
Because this pressure is often less than saturation, dissolved gases are released and flash evaporation can occur. Pressure recovery and recompression above ambient then follow. A simplistic version of the cycle is illustrated in Figure 1, for ambient pressures above the thermodynamic critical pressure.

It is unusual to have a subcritical region nested within a supercritical region without intervening physical barriers. Yet it has been demonstrated that two-phase flow cavities can be "nested" within a system with supercritical ambient pressure and that conditions for the existence of such nested cavities are prevalent for sharp-edge inlets and for eccentrically loaded high-performance turbomachines [7]. For the seal data of Figure 2 the working fluid was parahydrogen $\left(\mathrm{P}_{\mathrm{C}}=1.2928 \mathrm{MPa}, \mathrm{T}_{\mathrm{C}}=32.976 \mathrm{~K}\right.$, ${ }^{\circ} \mathrm{C}=31.4 \mathrm{~kg} / \mathrm{m}^{3}$ ) and the nonrotating shaft was fully eccentric. The pressure at the inlet to the third step was greater than $P_{C}$. However, immediately downstream of the step the pressure on one "side" of the seal $(\theta=0)$ remained above $P_{C}$ while the pressure on the opposite "side" $(\theta=\pi)$ was nearly equal to the saturation pressure $P_{S}$. Thus the circumferential pressure profile encompasses all states from $P_{\text {in }}>P_{C}$ at $\theta=0$ to $P_{S}$ at $\theta=\pi$ and represents a two-phase flow cavity nested within a supercritical pressure regime.

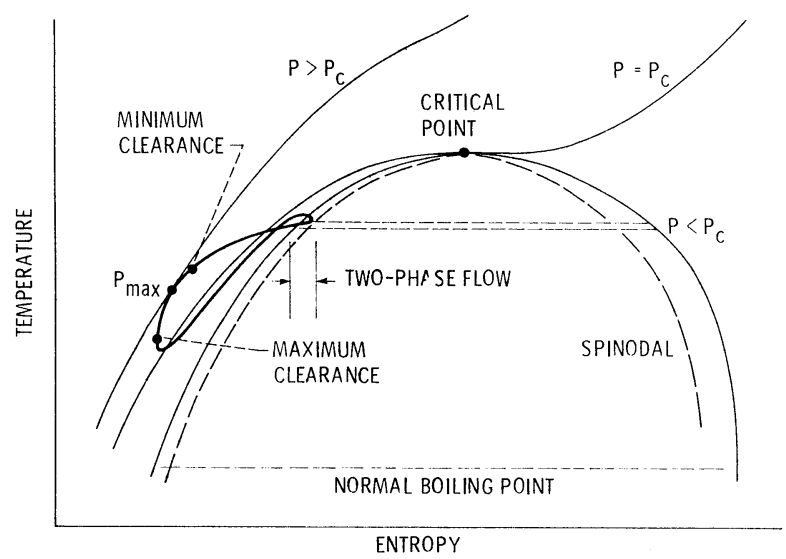

Figure 1 Temperature-entropy schematic. 


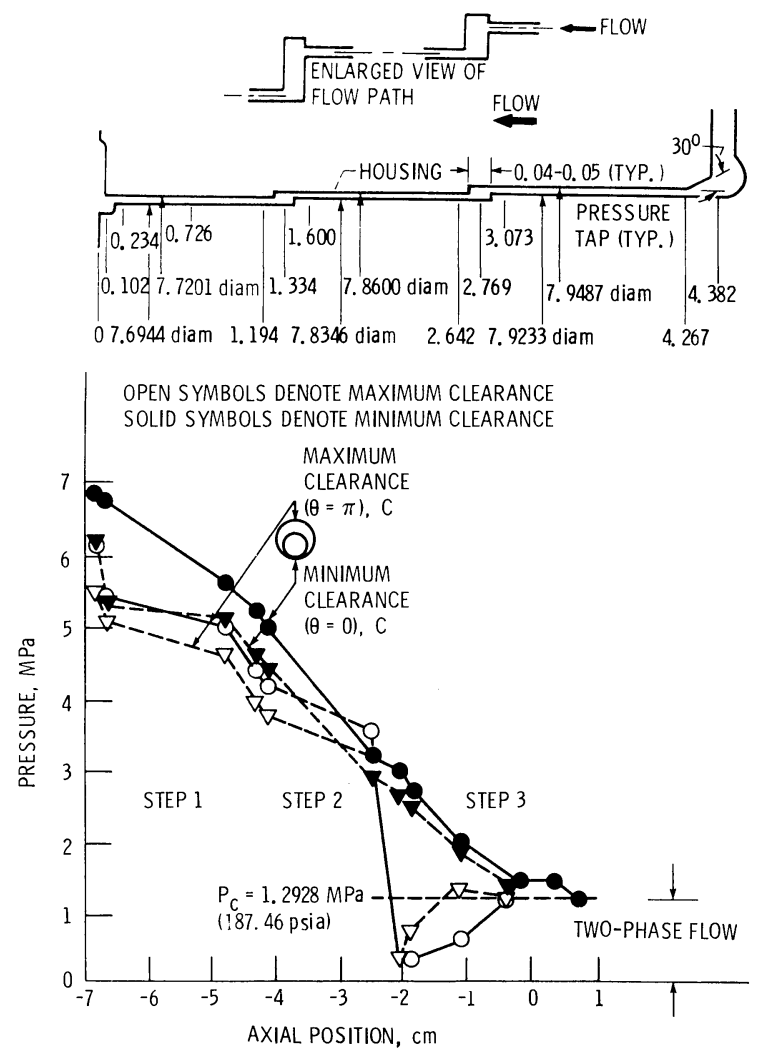

Figure 2 Pressure profile for fully eccentric, nonrotating, three-step space shuttle main engine (SSME) seal configuration.

An embedded two-phase flow cavity zone was calculated for a highly eccentric bearing

(Table 1) by using the constant-property Reynolds equations (no energy solution) for fluid hydrogen $[7]$. There are no corroborating data.

In this study we extend the investigation of nested subcritical pressure regions by using variable-property laminar conservation equations and apply the method of corresponding states to bearings.

\section{ANALYSIS}

The governing equations have been developed elsewhere [8] from the work of Dowson [9] and Fowles [10]. Only the basic form and assumptions are repeated herein.

\subsection{Assumptions}

1. The clearance/radius ratio is so small that the cylindrical system can be unwrapped and represented by a system of Cartesian coordinates with smooth boundaries.

2. The fluid is Newtonian, the flow is laminar, and inertia and body forces are neglected.

3. Velocity derivatives du/dy and $d v / d y$ are large compared with other gradients.

4. Fluid properties and clearance are functions of coordinates $(x, y, z)$.

The most questionable assumptions are that the walls are smooth and that high shear flows in narrow passages can be described in terms of laminar flows well beyond the usual range of
Reynolds numbers. In the authors' opinion, neglecting asperities and turbulence results in underprediction of viscous effects and would exacerbate the cavity zone formation. The consequences remain to be explored.

\subsection{Governing Equations}

The generalized Reynolds equation in the unwrapped Cartesian coordinates ( $x=$ circumferential, $z=$ axial) becomes

$$
\begin{aligned}
& \frac{\partial}{\partial X_{i}} \frac{\partial P}{\partial X_{i}}+\frac{1}{\hat{m}_{2}}\left[\frac{\partial \hat{m}_{2}}{\partial X_{i}} \frac{\partial P}{\partial X_{i}}+\frac{3}{h} \frac{\partial P}{\partial X_{i}} \frac{\partial h}{\partial X_{i}}\right] \\
& =\frac{R \Omega}{\hat{m}_{2} h}\left[\frac{\hat{m}_{1}}{F_{0}} \frac{\partial h}{\partial X_{i}}+h \frac{\partial}{\partial X_{i}}\left(\frac{\hat{m}_{1}}{F_{0}}\right)\right]+\rho \frac{\partial h}{\partial t}
\end{aligned}
$$

where

$$
\begin{aligned}
& \left.\left.\hat{m}_{2}=\left\{\frac{F_{1}}{F_{0}} \hat{m}_{1}-\int_{0}^{h(x, z)} \rho\right] \int_{0}^{\zeta} \frac{\zeta d \zeta}{n g_{c}}\right] d \zeta\right\} \frac{1}{h^{3}} \\
& \hat{m}_{1}=\left\{\int_{0}^{h(x, z)} \rho\left[\int_{0}^{\zeta} \frac{\zeta d \zeta}{n g_{c}}\right] d \zeta\right\} \frac{1}{h} \\
& F_{1}=\int_{0}^{h(x, z)} \frac{\zeta d \zeta}{n g_{c}} ; \quad F_{0}=\int_{0}^{h(x, z)} \frac{d \zeta}{n g_{c}}
\end{aligned}
$$

The energy equation becomes

$$
\frac{\partial \rho E}{\partial t}+\frac{u_{i}}{L} \frac{\partial \rho E}{\partial X_{i}}=-\frac{P}{L} \frac{\partial u_{k}}{\partial X_{k}}+\frac{1}{L^{2}} \frac{\partial}{\partial X_{i}}\left(\lambda \frac{\partial T}{\partial X_{i}}\right)+\varphi
$$

where $e=C T$ and $\varphi$ is viscous dissipation.

\subsection{Solution Method}

The Reynolds equation was solved first for the pressure and velocity fields. The properties were evaluated at each grid point as a function of pressure and temperature. With the new set of properties the energy equation was solved. The process was iterated until the pressure and temperature convergence criteria were met. The grid used was 11 axial by 33 circumferential. Doubling the grid did not have a significant effect on the computations, and continuity was checked at each point.

\section{RESULTS}

\subsection{Bearing}

The axial pressure gradients for a bearing are usually smaller than those for a seal, but the circumferential gradients are usually much 

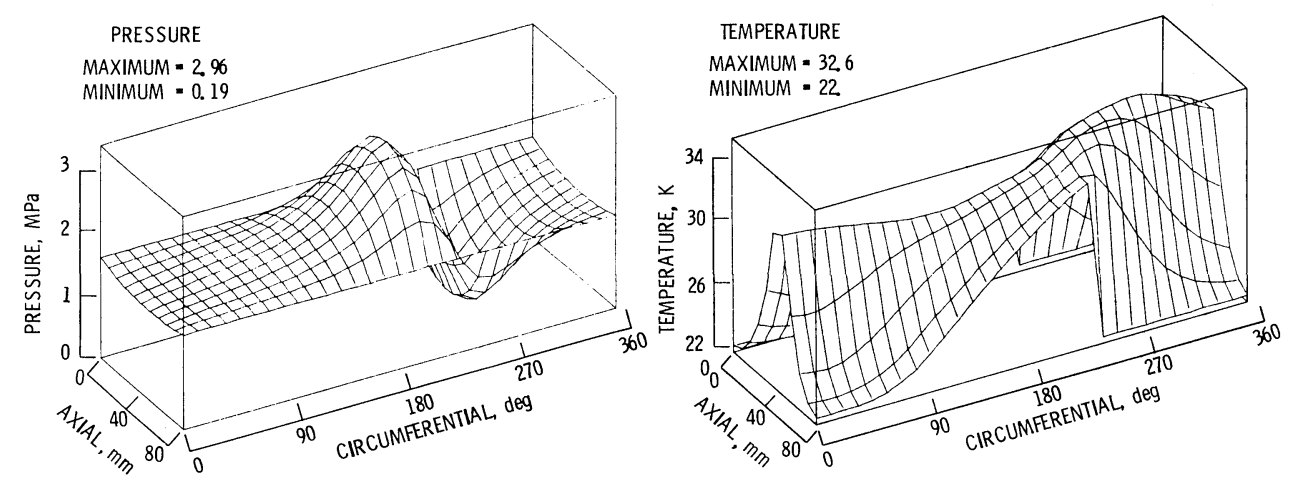

(a) Constant properties.
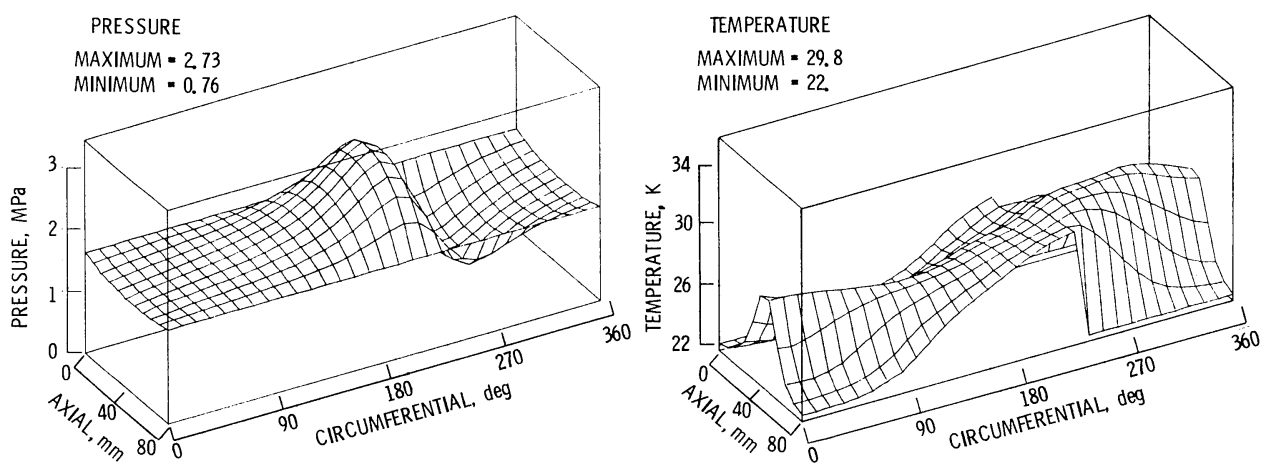

(b) Variable properties.

Figure 3 Analytic pressure and temperature surfaces for a bearing (Table 2) rotating at $90000 \mathrm{rpm}$.

larger. Both seals and bearings can be designed to take advantage of these pressure gradients to provide significant damping and stiffness, which enhance stability [11].

The pressure and temperature surfaces of Figure $3(a)$ represent the constant-property solution of the conservation equations for a rotational speed of $90000 \mathrm{rpm}$ for the bearing configuration of Table 2. The cavity pressure was significantly lower than the saturation pressure although the ambient pressure was above the critical pressure. A similar result was found, without heat transfer, for an ambient pressure about eight times the critical pressure [7], and the bearing was highly eccentric.

As the fluid approaches the minimum clearance, the temperature contours (Fig. 3(a)) become uniform, reflecting an increase in heat generation and axial convection out of the bearing. Immediately downstream of the minimum clearance, bulk fluid is convected into the bearing to provide cooling but does not penetrate into the cavity zone. The heat generated becomes trapped, and the temperature continues to increase.

Although solutions of the variable-property equations (Fig. 3(b)) indicated only about an 8 -percent reduction in peak pressure and temperature, the two-phase zone was all but eliminated and was represented by a single point.

Increasing the speed of rotation enlarged the two-phase zone. The pressure, temperature, viscosity, and heat capacity surfaces for this case are characterized in Figure 4 . The property variations were significant, and the profiles were not symmetric because of the 0.1-MPa difference in inlet and exit bearing pressures (Table 2). It is apparent that constant-property solutions tend to overpredict the load-carrying capacity and the extent of cavity formation. Note also that the thermal surface lagged the pressure surface and the energy was transported downstream. This is not always the case; for example, when asperity contacts occur, the classic Blok problem enters and heat is transported upstream (for fluid oil and low rotational speed) [12].

\subsection{Extended Corresponding States}

Often for fluid (a) for a bearing or seal an excellent equation of state and data exist but not for fluid (b). In such cases it would be valuable to have a method of evaluating the seal or bearing performance with fluid (b). For the infinite journal bearing the theoretical load $W$ supported by a stable constant-property $360^{\circ}$ fluid film depends on the bearing parameter $\Lambda$ $[1,13]$

$\left(\frac{W}{A \Delta P}\right)\left[\frac{\left(2+a^{2}\right) \sqrt{1-a^{2}}}{a}\right]=\frac{6 R L n \Omega}{c^{2} \Delta P}=\Lambda$

Here the classic form is used rather than $\left(1-a^{2}\right)$, which provides more realistic results [14], and $A$ is the surface area, $A=2 \pi R L$.

Using the extended principle of corresponding states $[15,16]$, it appears possible to predict bearing behavior for single-component fluids 

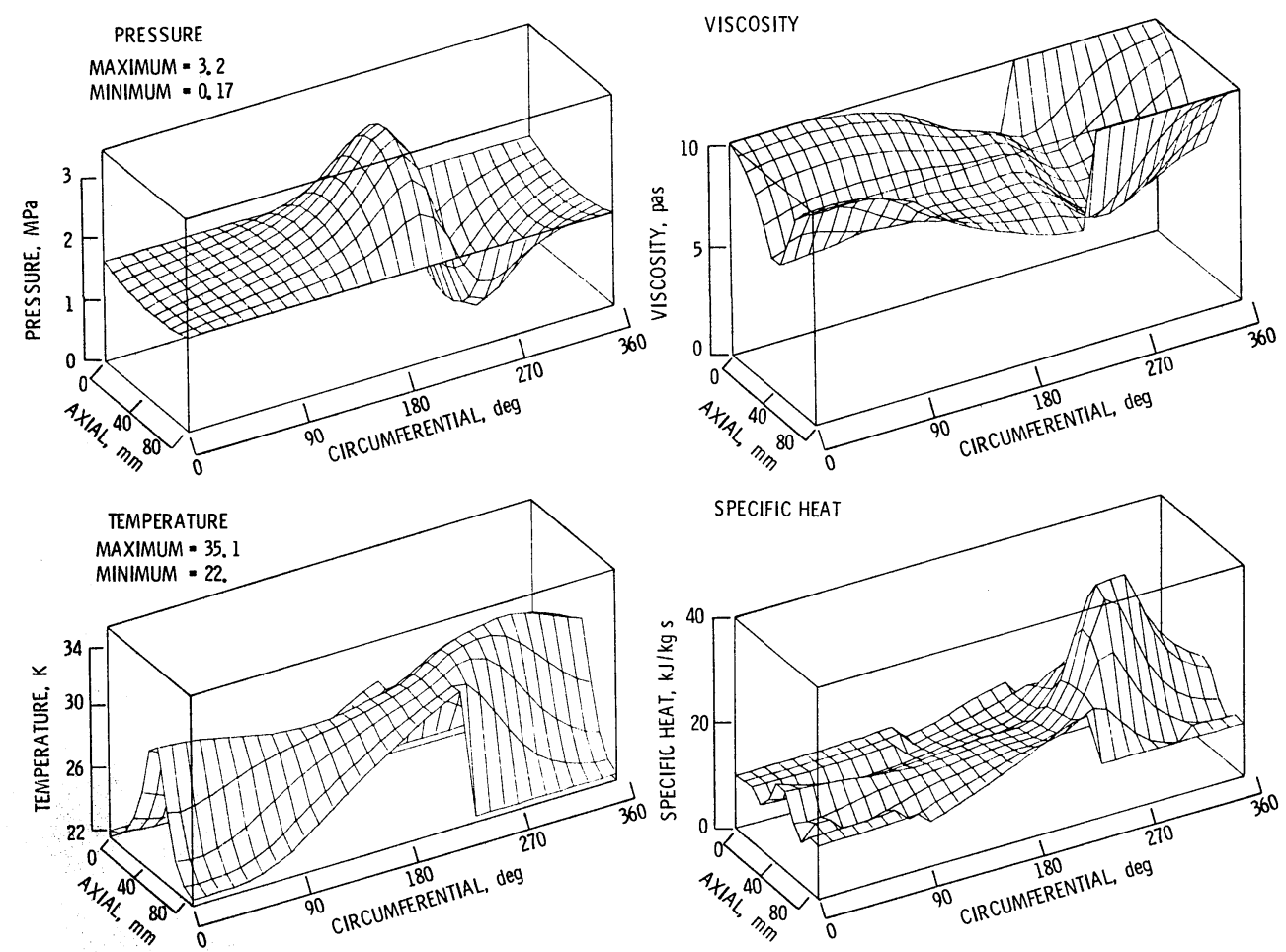

Figure 4 Analytic surfaces for a bearing (Table 2) rotating at $105000 \mathrm{rpm}$.

(and perhaps for multicomponent fluids) based on the known behavior of a reference fluid. Viscosity becomes

$\eta_{\alpha}(P, T)=\eta_{0}\left(P \frac{n_{1}}{f}, \frac{T}{f}\right) F_{n}$

and from equation (3)

$\Lambda_{\alpha}(P, T)=\Lambda_{0}\left(P \frac{h_{1}}{f}, \frac{T}{f}\right)$

where for one-component fluids

$$
\begin{aligned}
& F_{n}=\frac{\left(\frac{M_{\alpha}}{M_{0}} f\right)^{1 / 2}}{n_{1}^{2 / 3}} \\
& f=\left(\frac{T_{\alpha}^{C}}{T_{0}^{C}}\right) \theta ; \text { and } h_{1}=\left(\frac{v_{\alpha}^{c}}{V_{0}^{c}}\right) \Phi=\left(\frac{M_{\alpha} \rho_{0}^{c}}{M_{0} \rho_{\alpha}^{c}}\right) \Phi
\end{aligned}
$$

Example: Let the reference fluid (subscript 0) be oxygen and the working fluid (subscript $\alpha$ ) be nitrogen. The bearing temperature and pressure are $100 \mathrm{~K}$ and $1.5 \mathrm{MPa}$. Assuming constant properties and $\theta=\Phi=1$, solve equation (4) for nitrogen by using the thermophysical properties of oxygen.

First, we need the thermodynamic properties

\begin{tabular}{|c|c|c|c|c|c|c|c|}
\hline Fluid & $\begin{array}{l}T_{c}, \\
K\end{array}$ & $\begin{array}{l}\mathrm{P}_{\mathrm{C}}, \\
\mathrm{MPa}\end{array}$ & $\begin{array}{r}{ }^{\circ} \mathrm{C}^{\prime} \\
\mathrm{g} / \mathrm{cm}^{3}\end{array}$ & $\begin{array}{c}\text { M, } \\
\mathrm{g} / \mathrm{g} \text { mole }\end{array}$ & $f$ & $h_{1}$ & $F_{n}$ \\
\hline $\begin{array}{l}\mathrm{N}_{2} \\
\mathrm{O}_{2}\end{array}$ & $\begin{array}{l}126.3 \\
154.78\end{array}$ & $\begin{array}{l}3.417 \\
5.082\end{array}$ & $\begin{array}{r}0.3105 \\
.4325\end{array}$ & $\begin{array}{l}28.016 \\
31.9988\end{array}$ & 0.816 & 1.22 & 0.74 \\
\hline
\end{tabular}
at the critical point [17].

$$
\begin{aligned}
& \mathrm{P}_{0}=\mathrm{Ph}_{1} / \mathrm{f}=1.5 \times 1.22 / 0.816=2.242 \mathrm{MPa} \\
& \mathrm{T}_{0}=\mathrm{T} / \mathrm{f}=100 / 0.816=122.5 \mathrm{~K}
\end{aligned}
$$

For comparison, the constant-property Reynolds equation was first solved by using the bearing parameter for nitrogen at $\mathrm{P}=1.5 \mathrm{MPa}$ and $T=100 \mathrm{~K}$. Then the solution was repeated for the bearing parameter predicted for nitrogen based on oxygen properties at $P_{0}=2.242 \mathrm{MPa}$ and $T_{0}=122.5 \mathrm{~K}$. The reduced circumferential pressure profiles at the center of the bearing are illustrated in Figure 5 for nitrogen and for nitrogen predicted from oxygen properties. The agreement, within 5 percent, is better than expected as pressure predictions are less accurate than flow (continuity) predictions. This problem requires further exploration as the Reynolds equation is a form of the continuity equation.

\subsection{Boilers and Rotors}

A corollary class of nested two-phase flows occurs in the rotating boilers and cooled rotor windings of turbomachine systems. A rotating pressure containment vessel with axial flow 


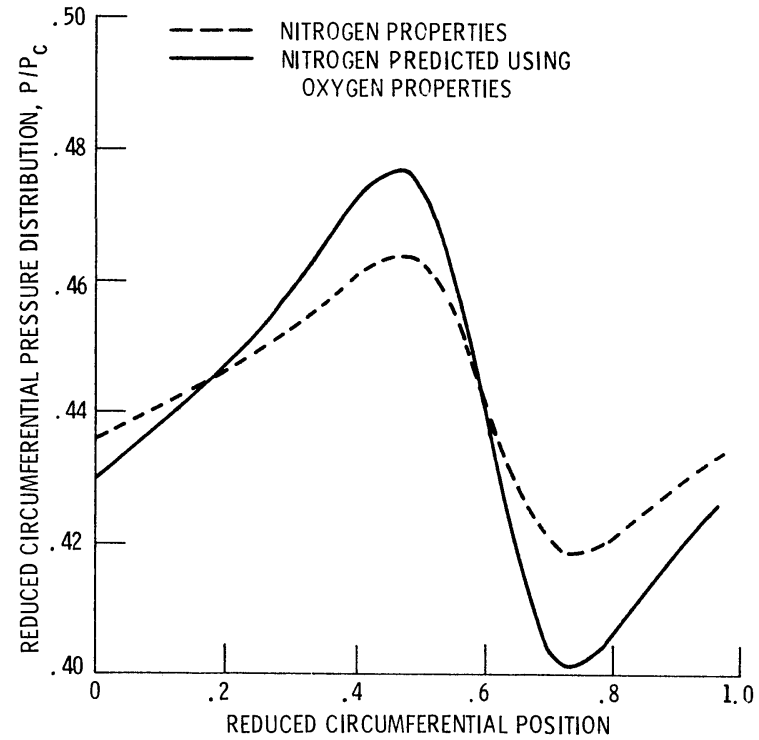

Figure 5 Reduced midbearing circumferential pressure profiles based on corresponding states for fluids nitrogen and oxygen.

produces centrifugal and Coriolis body forces. For a rotating cylindrical boiler the radial position of the critical pressure surface can be adjusted to occur very close to the wall or the fluid-vapor interface; the two-phase region is nested. A generic boiler configuration is given in Table 3.

Calculations for the generic boiler were carried out by using a rotary boiler code [18], with Freon-11 ( $\mathrm{P}_{\mathrm{C}}=4.41 \mathrm{MPa} ; \mathrm{T}_{\mathrm{C}}=471 \mathrm{~K}$; $\left.{ }^{o_{C}}=0.553 \mathrm{~g} / \mathrm{cm}^{3}\right)[19]$ as the working fluid. For the supercritical pressure regime the heat flux follows the metastable Leidenfrost and film boiling loci, and the body force dependency follow the $(0.25$ to 0.35$)$ power-law dependence [20]. Thus the prescribed wall heat flux becomes

$$
\frac{q_{n g}}{q_{1 g}}=n^{\left[0.25+0.02 \log _{10}(n)\right]}
$$

The solution converged for wall pressures less than $P_{C}$, but failed to converge for pressures greater than $P_{C}$ (conditions of Table 3 ). The problem was traced to the definition of Freon enthalpies in this region and requires a new equation of state. The properties code [17] is being integrated into the boiler code [18].

To the dynamicist the location and extent of the nested regions may become important only after the system instabilities are encountered.

\section{SUMMARY}

Analyses of bearings and seals have shown subcritical and two-phase cavity flow zones to be embedded within a supercritical pressure envelope. It is anticipated that rotating boilers $c$ an also have these zones. The nature of the transport within the near-critical region embedded within the fluid layer is largely unexplored.
For the bearing considered herein constantproperty solutions with no asperity contact tend to overpredict the load-carrying capacity and the extent of cavity formation, with the thermal surface lagging the pressure surface. Variable properties tend to smooth the surfaces and in some cases eliminate the two-phase cavity. In the authors' opinion, inclusion of turbulence would exacerbate the cavity formation, perhaps again approaching the constant-property case.

The method of extended corresponding states appears to be a reasonable approach to predicting the behavior of a bearing lubricated with fluid (b) from the data and equation of state for the bearing with reference fluid $(a)$.

\section{NOMENCLATURE}

clearance, $m$

c specific heat, $\mathrm{kJ} / \mathrm{kg} \mathrm{K}$

D diameter, $m$

E internal energy, $\mathrm{kJ} / \mathrm{kg}$

e eccentricity, m

$f, h_{1} \quad$ functions scaling working fluid to reference fluid

gacceleration (body force), $\mathrm{m} / \mathrm{s}^{2}$

$g_{C} \quad$ standard acceleration (body force), $\mathrm{m} / \mathrm{s}^{2}$

$h, h(x, z)$ dimensionless film thickness, $y / c$

$L \quad$ seal or bearing length, $m$

M molecular weight

$\mathrm{n}$ acceleration ratio, $\mathrm{g} / \mathrm{g}_{\mathrm{C}}$

P pressure, MPa

Pr reduced pressure, $P / P_{C}$

$q$ heat flux, $W / m^{2}$

radius, $m$

$\mathrm{S}$ entropy, $\mathrm{kJ} / \mathrm{kg} \mathrm{K}$

$T$ temperature, $K$

$t$ time, $s$

$x_{i} \quad$ coordinate $(x / L, z / L)$

$x$ circumferential coordinate, $m$

$y \quad$ clearance coordinate, $m$

$z$ axial coordinate, $m$

$n \quad$ viscosity, Pas

$\theta, \Phi \quad$ shape functions

$\theta \quad$ circumferential coordinate, rad

$\lambda$ thermal conduçtivity, $W / m K$

$\rho$ density, $\mathrm{kg} / \mathrm{m}^{3}$

$\Omega \quad$ angular velocity, $\mathrm{rad} / \mathrm{s}$

Subscripts superscript)

$s$ saturation

0 reference fluid

a working fluid

\section{REFERENCES}

1. Skripov, V.P., Metastable Liquids, John Wiley, New York, 1974

2. Frenkel, I., Kinetic Theory of Liquids, Dover Publications, New York, 1955.

3. Hendricks, R.C., Mullen, R.L., and Braun, M.J., Analogy Between Cavitation and Fracture Mechanics, in ASME/JSME Thermal Engineering Joint Conference Proceedings, vol. 1, eds. Y. Mori and W.J. Yang, pp. 35-42, ASME, New York, 1983. 
4. Holmes, R., On the Role of 0il-Film Bearings in Promoting Shaft Instability: Some Experimental Observations, in Rotordynamic Instability Problems in HighPerformance Turbomachinery, NASA CP-2133, 1980 , pp. 345-357.

5. Bently, D.E., and Muszynska, A., Stability Evaluation of Rotor/Bearing System by Perturbation Tests, in Rotordynamic Instability Problems in High-Performance Turbomachinery, NASA CP-2250, 1982, pp. 307-322.

6. Hendricks, R.C., A Comparative Evaluation of Three Shaft Seals Proposed for High Performance Turbomachinery, NASA TM-83021, 1982.

7. Hendricks, R.C., Braun, M.J., Wheeler, R.L., and Mullen, R.L., Nested Subcritical Flows Within Supercritical Systems, in Cavitation and Multiphase Flow Forum, eds. J.W. Hoyt and 0. Furuya, ASME FED-Vol. 23, ASME, New York, 1985.

8. Braun, M.J., Mullen, R.L., Hendricks, R.C., and Wheeler III, R.L., Development and Discussion of a Two-Phase Homogeneous Model for a Generalized Reynolds Equation, in Cavitation and Multiphase Flow Forum, eds. J.W. Hoyt and 0. Furuya, pp. 120-123, ASME FED-Vol. 23, ASME, New York, 1985.

9. Dowson, D., A Generalized Reynolds Equation for Fluid Film Lubrication. Int. J. Mech. Sci., vol. 4, pp. 159-170, $1 \overline{962}$.

10. FowTes, P.E., A Simpler Form of the General Reynolds Equation, J. Lubr. Technol., vol. 92, pp. 661-662, 1970.

11. Childs, D.W., Hendricks, R.C., and Vance, J.M., eds., Rotordynamic Instability Problems in High-Performance Turbomachinery, NASA CP-2133, 1980. (See also NASA CP-2250 (1982), and NASA CP-2338 (1984).)

12. Majumdar, B.C., and Hamrock, B.J., Effect of Surface Roughness on Hydrodynamic Bearings, NASA TM-81711, 1981.

13. Crandall, S.H., Heuristic Explanation of Journal Bearing Instability, in Rotordynamic Instability Problems in HighPerformance Turbomachinery, NASA CP-2250, 1982, pp. 274-283.

14. Bent1y, D.E., and Muszynska, A.: Instability in Rotating Machinery, in Instability in Rotating Machinery, NASA CP-2409, 1986 .

15. Mollerup, J., Correlated and Predicted Thermodynamic Properties of LNG and Related Mixtures in the Normal and Critical Regimes, in Advances in Cryogenic Engineering, ed. K.D. Timmerhaus, vol. 20, pp. 172-194, Plenum Press, New York, 1975.

16. Hendricks, R.C., and Sengers, J.V., Application of the Principle of Similarity to Fluid Mechanics, in Waier and Steam: Their Properties and Current Industrial Applications, eds. J. Straub and K. ScheffTer, pp. 322-335, Pergamon Press, 0xford, 1980. (Unabridged version as NASA TM X-79258, 1979.)
17. Hendricks, R.C., Baron, A.K., and Peller, I.C., GASP - A Computer Code for Calculating the Thermodynamic and Transport Properties for Ten Fluids: Parahydrogen, Helium, Neon, Methane, Nitrogen, Carbon Monoxide, 0xygen, Fluorine, Argon, and Carbon Dioxide, NASA TN D-7808, 1975.

18. Negreanu, M.J., An Investigation of a Rotational Boiler, Ph.D. Thesis, CarnegieMellon University, Pittsburgh, PA, 1978.

19. Thermodynamic Properties of Freon-11 Refrigerant (Trichlorofluoromethane). Report T-11, E.I. Dupont, 1965.

20. Graham, R.W., Hendricks, R.C., and Ehlers, R.C., An Experimental Study of the Pool Boiling Heating of Liquid Hydrogen in the Subcritical and Supercritical Pressure Regimes over a Range of Accelerations, in Int. Advances in Cryogenic Engr., ed. K.D. Timmerhaus, pp. 342-352, PTenum Press., New York, 1965.

TABLE 1. ANALYTICAL BEARING PARAMETERS

\begin{tabular}{|c|c|}
\hline Geometric & \\
\hline Diameter, mm (in.) ... & $.25 .4(1)$ \\
\hline $\begin{array}{l}\text { Length, } m m(\text { in.) } \\
\text { Clearance, } m m \text { (in.) }\end{array}$ & $-\dot{1}^{25.4}(1)$ \\
\hline Eccentricity. . . . & $\begin{array}{r}0.0234(0.001) \\
. .0 .0 .97\end{array}$ \\
\hline Hydrodynamic & \\
\hline Inlet pressure, $\mathrm{MPa}$ (psia) & $13.8(2000)$ \\
\hline Exit pressure, $\mathrm{MPa}$, (psia) & $.13 .45(1950)$ \\
\hline Maximum pressure, MPa (psia) & .27 .16( \\
\hline Minimum pressure, MPa (psia) & $0.079(11.5)$ \\
\hline Inlet temperature, $K\left({ }^{\circ} \mathrm{R}\right)$ & $.20(36)$ \\
\hline Speed, $\mathrm{rad} / \mathrm{s}(\mathrm{rpm}) \ldots$ & $7850(75000)$ \\
\hline
\end{tabular}

TABLE 2. BEARING PARAMETERS

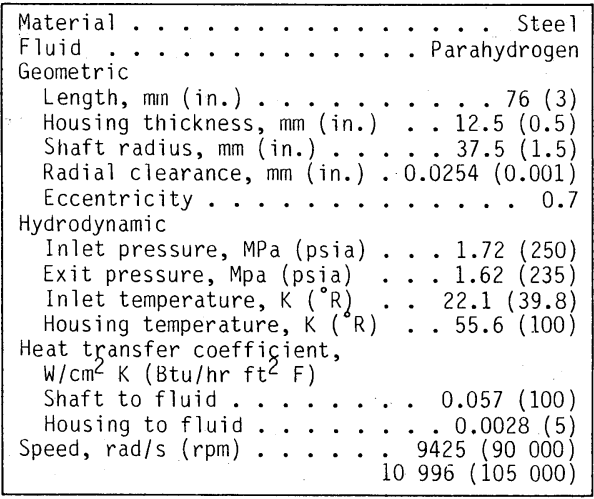

TABLE 3. ROTATING BOILER PARAMETERS

External fins, mm (in.) .... $13(0.5)$ Wall thickness, mm (in.) ... . 13 (0.5) Container radius, mm (in.) . . . 100 (4) Vapor interface radius, mm (in.) . . 25 (1) Length, mm (in.) ..... 300 (12) Speed, $\mathrm{rad} / \mathrm{s}(\mathrm{rpm}) . . .576$ (5500) Wall pressure, MPa (psia) . . $4.62(670)$

Inlet pressure, $\mathrm{MPa}(\mathrm{psia}) . .3 .1$ (450) 


\begin{tabular}{|c|c|c|c|}
\hline $\begin{array}{l}\text { 1. Report No. } \\
\text { NASA TM-87228 }\end{array}$ & 2. Government Accession No. & \multicolumn{2}{|c|}{ 3. Recipient's Catalog No. } \\
\hline \multirow{2}{*}{\multicolumn{2}{|c|}{$\begin{array}{l}\text { 4. Title and Subtitle } \\
\text { Two-Phase Flows and Heat Transfer Within Systems } \\
\text { With Ambient Pressure Above the Thermodynamic } \\
\text { Critical Pressure }\end{array}$}} & \multicolumn{2}{|l|}{ 5. Report Date } \\
\hline & & \multicolumn{2}{|c|}{$\begin{array}{l}\text { 6. Performing Organization Code } \\
505-62-21\end{array}$} \\
\hline \multirow{2}{*}{\multicolumn{2}{|c|}{$\begin{array}{l}\text { 7. Author(s) } \\
\text { R.C. Hendricks, M.J. Braun, and R.L. Mullen }\end{array}$}} & \multicolumn{2}{|c|}{$\begin{array}{l}\text { 8. Performing Organization Report No. } \\
\text { E-2897 }\end{array}$} \\
\hline & & \multicolumn{2}{|l|}{ 10. Work Unit No. } \\
\hline \multirow{2}{*}{\multicolumn{2}{|c|}{$\begin{array}{l}\text { 9. Performing Organization Name and Address } \\
\text { National Aeronautics and Space Administration } \\
\text { Lewis Research Center } \\
\text { Cleveland, Ohio } 44135\end{array}$}} & & \\
\hline & & \multicolumn{2}{|c|}{ 11. Contract or Grant No. } \\
\hline \multirow{2}{*}{\multicolumn{2}{|c|}{$\begin{array}{l}\text { 12. Sponsoring Agency Name and Address } \\
\text { National Aeronautics and Space Administration } \\
\text { Washington, D.C. } 20546\end{array}$}} & \multicolumn{2}{|c|}{$\begin{array}{l}\text { 13. Type of Report and Period Covered } \\
\text { Technical Memorandum }\end{array}$} \\
\hline & & \multicolumn{2}{|c|}{ 14. Sponsoring Agency Code } \\
\hline \multicolumn{4}{|c|}{$\begin{array}{l}\text { 15. Supplementary Notes } \\
\text { Prepared for the Eighth International Heat Transfer Conference, San Francisco, } \\
\text { California, August } 17-22 \text {, 1986. R.C. Hendricks, NASA Lewis Research Center; } \\
\text { M.J. Braun, University of Akron, Akron, Ohio 44325; R.L. Mullen, Case Western } \\
\text { Reserve University, Cleveland, Ohio } 44106\end{array}$} \\
\hline \multicolumn{4}{|c|}{$\begin{array}{l}\text { 16. Abstract } \\
\text { In systems where the design inlet and outlet pressures } P_{\text {amb are maintained }} \\
\text { above the thermodynamic critical pressure } P_{c} \text {, it is often assumed that heat } \\
\text { and mass transfer are governed by single-phase relations and that two-phase flows } \\
\text { cannot occur. This simple rule of thumb is adequate in many low-power designs } \\
\text { but is inadequate for high-performance turbomachines, boilers, and other systems } \\
\text { where two-phase regions can exist even though } P_{\text {amb }}>P_{C} \text {. Heat and mass } \\
\text { transfer and rotordynamic-fluid-mechanic restoring forces depend on momentum } \\
\text { differences; and those for a two-phase zone can differ significantly from those } \\
\text { for a single-phase zone. By using a laminar, variable-property bearing code and } \\
\text { a rotating boiler code, pressure and temperature surfaces were determined that } \\
\text { illustrate nesting of a two-phase region within a supercritical pressure region. } \\
\text { The method of corresponding states is applied to bearings with reasonable } \\
\text { rapport (within } 5 \text { percent for an oxygen/nitrogen example). }\end{array}$} \\
\hline $\begin{array}{l}\text { 17. Key Words (Suggested by Autho } \\
\text { Two-phase; Bearing } \\
\text { Corresponding stat }\end{array}$ & $\begin{array}{l}\text { 18. Distribu } \\
\text { Uncla } \\
\text { STAR }\end{array}$ & $\begin{array}{l}\text { ent } \\
\text { ry } 34\end{array}$ & \\
\hline $\begin{array}{l}\text { 19. Security Classif. (of this report) } \\
\text { Unc lass if ied }\end{array}$ & $\begin{array}{l}\text { Security Classif. (of this page) } \\
\text { Unc lass if ied }\end{array}$ & 21. No. of pages & 22. Price* \\
\hline
\end{tabular}

